\title{
Quality of life of children and adolescents with rheumatic fever
}

\author{
Márcia F. C. Carvalho, ${ }^{1}$ Katia V. Bloch, ${ }^{2}$ Sheila K. F. Oliveira ${ }^{3}$
}

\begin{abstract}
Objective: To assess the quality of life of patients with rheumatic fever receiving outpatient treatment at two hospitals.

Methods: Cross-sectional study using the Child Health Questionnaire (CHQ) administered to the parents of 133 patients with rheumatic fever aged between 5 and 18 years. The scores of the several dimensions of the questionnaire were calculated and compared within the categories of clinical and sociodemographic variables using a nonparametric test.

Results: Patients' age ranged from 5 to 18 years old, with a mean age of 12 years and standard deviation of 2.8 years. The most common manifestation of the disease was articular symptoms associated with cardiac problems, present in 74 cases $(56.1 \%)$. Most patients belonged to low-income families. Subjects had higher scores on the following concepts of the questionnaire: physical functioning, role/social-physical; role/social-emotional/behavioral; bodily pain; and family activities. The items with the lowest scores were: family cohesion; general health; global behavior; and parental impact-emotional. Girls had higher scores on: self-esteem; role/social-emotional/behavioral; and general health. Patients belonging to middle-income families had higher scores on: mental health; physical functioning; role/social-physical; and family activities. Children from the lowest social class had higher scores on bodily pain and psychosocial aspects.

Conclusions: The quality of life of patients with rheumatic fever is similar to that of patients with other chronic diseases, showing intermediate scores on the several concepts included both in the physical and the psychosocial domains. Social class was the variable most frequently associated with the CHQ concepts.
\end{abstract}

J Pediatr (Rio J). 2009;85(5):438-442: Rheumatic fever, quality of life, child, adolescent.

\section{Introduction}

Quality of life is a very subjective concept and it can be defined as the perception of the individuals of their own position in life in the context of the culture and value systems of the country where they live in relation to their goals, expectations, standards, and concerns. ${ }^{1}$ When trying to identify the aspects of life that are the most deeply affected by the disease and/or treatment, patients with chronic diseases reveal stronger concerns.

Rheumatic fever requires long-term prophylactic treatment, including painful administration of intramuscular medication, which can result in frequent psychological disorders and treatment dropout. Another factor that contributes to deteriorate the patient's quality of life is the presence of cardiopathies, which may cause functional and psychosocial limitations. $^{2}$

Several questionnaires have been validated to assess the quality of life of adults. ${ }^{1,3}$ For children, the most often used generic questionnaire is the Child Health Questionnaire (CHQ), which encompasses mainly physical, psychosocial, self-esteem, and family domains. This instrument enables the comparison of results among different diseases and features a version to be answered by the guardians of children older than 5 years and a version for adolescents and children older than 10 years. The scores for each scale

1. Mestre, Medicina, Programa de Saúde da Criança e do Adolescente, Faculdade de Medicina, Universidade Federal do Rio de Janeiro (UFRJ), Rio de Janeiro, RJ, Brazil.

2. Doutora, Saúde Pública, Universidade Federal da Bahia (UFBA), Salvador, BA, Brazil.

3. Doutora, Medicina, UFRJ, Rio de Janeiro, RJ, Brazil.

This study was conducted at the Institute of Child Care and Pediatrics Martagão Gesteira, Universidade Federal do Rio de Janeiro (UFRJ), Rio de Janeiro, RJ, Brazil.

No conflicts of interest declared concerning the publication of this article.

Suggested citation: Carvalho MF, Bloch KV, Oliveira SK. Quality of life of children and adolescents with rheumatic fever. J Pediatr (Rio J). 2009;85(5):438-442. Manuscript submitted Mar 31 2008, accepted for publication June 172009.

doi:10.2223/JPED. 1924 
ranges from 0 to 100, and the highest scores reflect better health status. The results of the $\mathrm{CHQ}$ have been presented for each different domain separately or as combined measures assessing all the measures that make up the physical and psychosocial scores. The psychometric properties of this questionnaire justify its use in prognostic studies with pediatric patients. 3,4

The CHQ was developed using some chronic diseases as clinical models. The scores revealed in these groups are presented in Table 1, as well as the scores resulting from the administration of the questionnaire to healthy children in the study that validated the instrument in Brazil. $5-10$

The objective of the present study is to assess the quality of life of patients with rheumatic fever receiving outpatient treatment at two public hospitals that are centers of excellence for the treatment of rheumatic fever in the municipality of Rio de Janeiro (RJ).

\section{Methods}

We conducted a cross-sectional study to assess the quality of life of patients with rheumatic fever.

The population of the present study included patients with rheumatic fever from a pediatric university hospital and public hospital specialized in heart diseases. The samples consisted of patients with rheumatic fever who were consecutively seen from January 2005 to October 2007. The inclusion criteria were: patients with diagnosis of acute rheumatic fever (established by the presence of two Jones major criteria, or one major criterion and two minor criteria associated with evidence of previous streptococcal infection) or with previous diagnosis of rheumatic fever, aged between 5 and 18 years old, and written informed consent signed by the guardians. The present study was approved by the Research Ethics Committee of both institutions.

Socioeconomic classification was established based on the assessment form of the Brazilian Association of Survey Companies (Associação Nacional de Empresas de Pesquisa). Families were classified as follows: class A - upper class; class B1 - upper middle class; class B2 - middle class; class C - lower middle class; class D - poor; class E - very poor.

\section{Description of the items included in the CHQ scale:}

- Physical functioning (PF) - Assesses the presence and extent of the physical limitations due to disease-related health problems.

- Role/social-physical (RP) - Assesses the physical activity at school and with friends.

- General health (GH) - Subjective measurement of health and disease. Parents answer questions that best describe their children's current, past and future health status.

- Bodily pain/discomfort (BP) - Used as an indicator of physical health.

- Parental impact-time (PT) - Assesses the time parents spend with medical treatment, emotional well-being, education, social life and behavior of the child/ adolescent.

- Parental impact-emotional (PE) - Assesses parents' concern with each one of these areas: physical health, emotional well-being, education, sociability and behavior of the child/adolescent.

Table 1 - Median for the different items of the Child Health Questionnaire obtained from clinical models and healthy children

\begin{tabular}{|c|c|c|c|c|c|c|}
\hline Item & $\begin{array}{c}\text { ADD } \\
(n=83)\end{array}$ & $\begin{array}{l}\text { Asthma } \\
(n=158)\end{array}$ & $\begin{array}{l}\text { PsychD } \\
(n=82)\end{array}$ & $\begin{array}{c}\text { JIA } \\
(n=74)\end{array}$ & $\begin{array}{l}\text { Epilepsy } \\
(n=34)\end{array}$ & $\begin{array}{l}\text { Healthy children } \\
\quad(\mathrm{n}=314) *\end{array}$ \\
\hline PF & 100.0 & 88.9 & 100.0 & 86.1 & 100.0 & 98.5 \\
\hline $\mathrm{RP}$ & 100.0 & 100.0 & 100.0 & 100.0 & 100.0 & 98.0 \\
\hline $\mathrm{GH}$ & 83.8 & 60.0 & 72.0 & 60.0 & 60.0 & 78.3 \\
\hline BP & 100.0 & 80.0 & 100.0 & 60.0 & 100.0 & 94.2 \\
\hline FA & 66.7 & + & + & + & + & 90.5 \\
\hline REB & 77.8 & 100.0 & 100.0 & 100.0 & 100.0 & 97.1 \\
\hline PT & 77.8 & 88.9 & + & 94.4 & 80.6 & 94.2 \\
\hline PE & 58.3 & 79.2 & + & 75.0 & 58.3 & 82.3 \\
\hline SE & 62.5 & 87.5 & + & 83.3 & 75.0 & 90.3 \\
\hline $\mathrm{MH}$ & 65.0 & 80.0 & 65.0 & 80.0 & 80.0 & 78.2 \\
\hline$B E$ & 55.5 & 75.0 & 60.0 & 80.0 & 70.8 & 79.5 \\
\hline FC & + & + & + & + & 100.0 & 78.1 \\
\hline PhS & 58.9 & 49.4 & + & 35.3 & 52.4 & 55.1 \\
\hline PsS & 37.1 & 52.9 & + & 49.8 & 46.0 & 53.0 \\
\hline
\end{tabular}

$\mathrm{ADD}=$ attention deficit disorder $\mathrm{BE}=$ global behavior; $\mathrm{BP}=$ bodily pain/discomfort; $\mathrm{FA}=$ limitation of family activities; $\mathrm{FC}=$ family cohesion; $\mathrm{GH}=\mathrm{general}$ health; $\mathrm{JIA}=$ juvenile idiopathic arthritis; $\mathrm{MH}=$ mental health; $\mathrm{PE}=$ parental impact-emotional; $\mathrm{PF}=$ physical functioning; $\mathrm{PhS}=$ physical $\mathrm{score}$; $\mathrm{PsS}=\mathrm{psychosocial}$ score; PsychD = psychiatric disease; PT = parental impact-time; REB = role/social-emotional/behavioral; RP = role/social-physical; SE = self-esteem.

* Mean.

$\dagger$ Item not analyzed in the questionnaire. 
- Role/social-emotional/behavioral (REB) - Assesses social, emotional and behavioral difficulties during the previous 4 weeks.

- Self-esteem (SE) - Assesses this important multidimensional concept, especially in pre-adolescents and adolescents.

- Mental health ( $\mathrm{MH}$ ) - Assesses the frequency of positive and negative mental aspects.

- Global behavior(BE) - Assesses behavior as a component of mental health.

- Family activities (FA) - Assesses the frequency of interruptions in the family daily activities during the previous 4 weeks.

- Family cohesion (FC) - Assesses general family relationships.

- CHANGE - Assesses the perception of changes in the health status during the past year.

- BEHAV - Assesses behavior during school activities and with friends.

The administration of the CHQ was authorized by its copyright holders by means of an agreement. The $\mathrm{CHQ}$ was administered by the researcher (the only interviewer) to all guardians before or after the medical visit scheduled for the patient's routine follow-up. Initially, there was an attempt of using a self-administration method (10 first interviewees), but this strategy resulted in a high rate of unanswered questions; thus we decided to conduct direct interviews. The interviews lasted in average 15 to 20 minutes, with great collaboration and interest from the guardians and patients. The interviewees did not have difficulties to understand the questions.

The CHQ data were analyzed using a computer program provided by HealthAct, which holds the copyright of the $\mathrm{CHQ}$. This computer program calculates the score for each domain and provides two measures obtained by means of weighting algorithms.

Univariate and bivariate analyses were carried out for the scores of different dimensions, comparing the scores of different categories of clinical and sociodemographic variables. A nonparametric test was used (median test) for score comparison purpose. This test compares the proportion of values higher than the median of the total population in each group. With values equal to the median, these values were distributed as if they were higher than the median.

The computer program Stata SE version 9 was used for data analysis.

\section{Results}

One hundred and thirty-three patients were assessed using the $\mathrm{CHQ}$. All individuals accepted to participate in the study. The patients' sociodemographic characteristics are shown in Table 2. Approximately $50 \%$ of the children included in our sample were being treated at each institution. As we could not find significant differences between the patients of both hospitals in terms of sex, age, and clinical characteristics, their results were not separated for presentation purposes.

Table 2 - Patients' sociodemographic characteristics

\begin{tabular}{lcc}
\hline Characteristics & $\mathbf{n}$ & \% \\
\hline Sex & & \\
$\quad$ Male & 68 & 51.5 \\
$\quad$ Female & 65 & 48.5 \\
Age & & \\
$<10$ years old & 29 & 21.8 \\
10-14 years old & 72 & 54.1 \\
$>14$ years old & 32 & 24.1 \\
Social class & & \\
B1 & 13 & 9.8 \\
B2 & 3 & 2.3 \\
C & 76 & 57.1 \\
D & 40 & 30.1 \\
E & 1 & 0.7 \\
Number of siblings & & \\
None & 10 & 7.5 \\
1 & 37 & 27.8 \\
2 & 38 & 28.6 \\
3 & 22 & 16.5 \\
4 or more & 26 & 19.6 \\
\hline
\end{tabular}

There was not prevalence of gender in the distribution of patients.

The patients' age ranged between 5 and 18 years old. Their mean age was 12 years old and the standard deviation was 2.8 years. More than $50 \%$ of the patients were aged from 10 to 14 years.

With regard to the disease manifestation, the most common one was articular symptoms associated with cardiac problems, which were present in 74 cases $(56.1 \%)$, followed by cardiac problems alone in 27 cases (20.5\%), 16 cases of articular symptoms alone $(12.1 \%)$, one case of chorea $(0.76 \%)$, and a combination of different manifestation in the remaining cases.

Most patients' families belonged to social class $\mathrm{C}$, whereas classes $C$ and $D$ together accounted for $90 \%$ of the families.

The majority of the patients had up to two siblings, although almost $20 \%$ of them had four or more siblings.

Only 16 patients (12\%) were going through the acute phase of the disease, while 117 (88\%) were being followed up due to rheumatic heart disease (chronic phase). The percentages of patients who had higher scores than the global median on the physical domain (acute phase, $46.7 \%$ vs. chronic phase, $50.5 \% ; p=1.0$ ) and on the psychosocial domain (acute phase, $60.0 \%$ vs. chronic phase, $48.6 \%$; 
$p=0.58$ ) were similar for both groups. The subsequent analyses included all patients.

The analysis of the $\mathrm{CHQ}$ items is shown in Figure 1. The children of our sample had better scores on the following items: PF, RP, REB, BP, and FA. The items with the lowest scores were: $\mathrm{FC}, \mathrm{GH}, \mathrm{BE}$, and $\mathrm{PE}$.

The analysis of the scores on the $\mathrm{CHQ}$ items according to sex revealed a statistically significant difference for SE $(p=0.03)$, REB $(p=0.02)$, and $G H(p=0.04)$, with females having higher scores.

The scores on the $\mathrm{CHQ}$ items according to different age groups only showed a statistically significant difference ( $p=0.02$ ) for PF of male patients. Those patients between 10 and 14 years old had higher scores than the median, whereas adolescents older than 14 years old had lower medians. The analysis of the $\mathrm{CHQ}$ items regarding the different age groups for the female population did not show statistically significant difference for any of the items.

Figure 2 shows the $\mathrm{CHQ}$ items according to the different social classes. We decided to join the data related to classes $D$ and $E$, thus making up the social class $D / E$, since there was only one case classified as class $E$. The items showing statistically significant difference were $\mathrm{MH}, \mathrm{PF}, \mathrm{RP}$, and $\mathrm{FA}$, which had higher scores in class $\mathrm{B}$, and REB and $\mathrm{BP}$, with higher scores in class D/E.

\section{Discussion}

The present study confirms the data of the literature regarding the characteristics of rheumatic fever manifestation. Articular symptoms associated with cardiac problems was the most common form of manifestation, followed by cardiac symptoms alone, being more prevalent

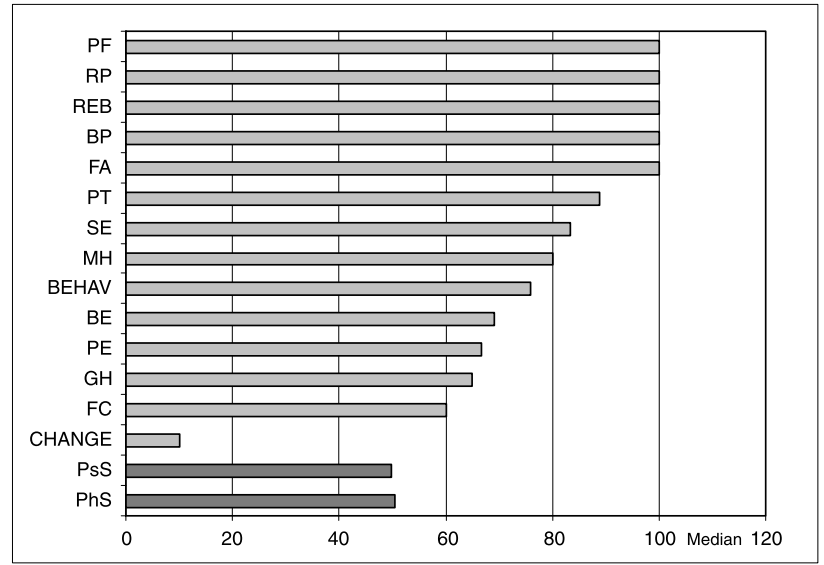

$\mathrm{PF}=$ physical functioning; $\mathrm{RP}=$ role/social-physical $\mathrm{REB}=$ role/social-emotional $/$ behavioral; $\mathrm{BP}=$ bodily pain/discomfort; $\mathrm{FA}$ = limitation of family activities; $\mathrm{PT}$ = parental impact-time; $\mathrm{SE}=$ self-esteem; $\mathrm{MH}=$ mental health; $\mathrm{BEHAV}=$ behavior; $\mathrm{BE}=$ global behavior; $\mathrm{PE}=$ parental impact-emotional; $\mathrm{GH}=$ general health; $\mathrm{FC}=$ family cohesion; $\mathrm{CHANGE}=$ change in health; $\mathrm{PSS}=$ psychosocial score; $\mathrm{PhS}=$ physical score

Figure 1 - Distribution of scores on the items of the Child Health Questionnaire

than articular problems alone. Such finding is not in agreement with the literature, which reports the articular symptoms as the most common form of manifestation of the disease. However, our study was conducted at hospitals that are centers of excellence for heart diseases, which might have contributed to a selection bias, increasing the proportion of cases with cardiac problems.

The literature on the assessment of quality of life in patients with rheumatic fever is rare despite the availability of questionnaires developed and validated to assess children with chronic diseases. ${ }^{11-13}$

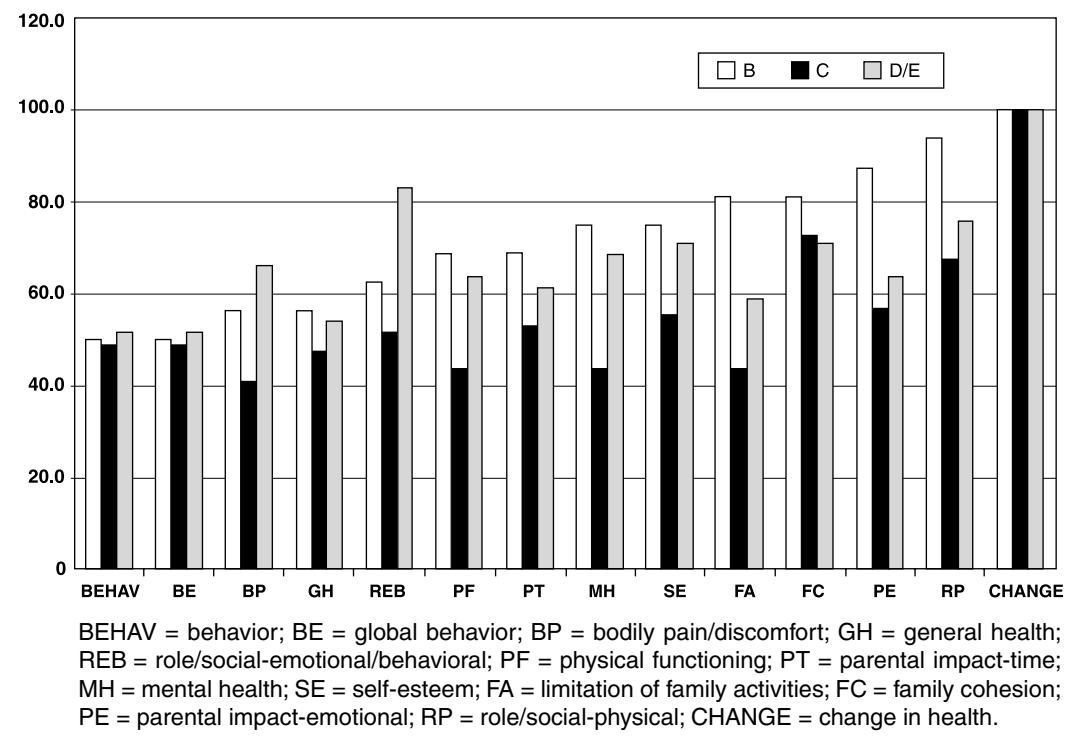

Figure 2 - Percentage of individuals belonging to the social class showing a median score higher than the median of the total population 
The result shown by the $\mathrm{CHQ}$ of patients with rheumatic fever revealed median values similar to those found in other studies involving children with chronic diseases such as: attention deficit disorder, asthma, epilepsy, psychiatric diseases, juvenile idiopathic arthritis, among others. 3,5,7,9-12 When analyzing the results of healthy Brazilian children on the $\mathrm{CHQ}$, we found that they had lower scores on CHANGE, followed by alterations on BE and PE. ${ }^{6}$

Some studies have used other generic questionnaires, such as the Peds QLTM, which was administered to children with chronic diseases and their guardians, and these studies have found discordant results regarding the quality of life of the children investigated. ${ }^{14}$

The analysis of our sample according to social class showed a stronger influence on the scores on $\mathrm{MH}, \mathrm{PF}, \mathrm{FA}$, and $\mathrm{RP}$, which were higher in social class $\mathrm{B}$ (the class with better socioeconomic status in our sample). Nevertheless, REB and $\mathrm{BP}$ showed higher scores in social class D/E. These findings evidence the importance of social conditions for disease perception and quality of life, mainly when there is need of long-term follow-up. It is worth mentioning that this aspect has not been highlighted in other studies; however, it was highly relevant for rheumatic fever, showing some significant results in several items analyzed in the present study.

The analyses of the combined measures assessing physical and psychosocial scores evidenced little difference in comparison with the scores of healthy children or children with some other types of chronic disease. ${ }^{5,6}$

The $\mathrm{CHQ}$ was also used to assess the quality of life of children with bowel movement disorders, who had significantly lower physical and psychosocial scores than healthy children. 15

The main limitations of our study were: the small size of the sample, as well as the slight variability in the subjects' socioeconomic characteristics, which might have impaired the detection of even higher differences in the quality of life. As it is the case of any cross-sectional study, there might be few patients with characteristics that decrease the survival rate. Another limitation is the fact that the interviews were done with the parents. Since one of the inclusion criterion was being aged between 5 and 18 years, we could not used the version of the questionnaire answered by children older than 10 years old and adolescents. Therefore, we decided to use the parent version (CHQ-50). A better option would be to administer the questionnaire to parents and children/adolescents, thus having a higher rate of agreement regarding the results for the physical domains and a lower rate of agreement for the social and emotional domains ${ }^{16}$ between the questionnaires.

We conclude that the quality of life of patients with rheumatic fever was similar to that found in children with other chronic diseases, both in terms of physical and psychosocial domains, and that socioeconomic factors are associated with differences in the quality of life.
We recommend the use of the $\mathrm{CHQ}$ in the beginning of the follow-up of patients with rheumatic fever with the purpose of helping to define their profile of quality of life. Re-administration of the questionnaire during the treatment may be useful to assess interventions and to plan new actions.

\section{References}

1. Seidl EM, Zannon CM. Qualidade de vida e saúde: aspectos conceituais e metodológicos. Cad Saude Publica. 2004;20:580-8.

2. Lima $A B$, Barros $M$, Santos $M$. Descrição dos indicadores sociais em adolescentes portadores de febre reumática. Revista da SOCERJ. 2005; 18:30-5.

3. Raat H, Bonsel GJ, Essink-Bot ML, Landgraf JM, Gemke RJ. Reliability and validity of comprehensive health status measures in children: The Child Health Questionnaire in relation to the Health Utilities Index. J Clin Epidemiol. 2002;55:67-76.

4. Rajmil L, Herdman M, Fernandez de Sanmamed MJ, Detmar S, Bruil J, Ravens-Sieberer $U$, et al. Generic health-related quality of life instruments in children and adolescents: a quality analysis of content. J Adolesc Health. 2004;34:37-45.

5. Landgraf JM, Abetz L, Ware JE. The CHQ: A User's Manual . Boston, MA: HealthAct; 1999.

6. Machado CS, Ruperto N, Silva CH, Ferriani VP, Roscoe I, Campos LM, et al. The Brazilian version of the Childhood Health Assessment Questionnaire (CHAQ) and the Child Health Questionnaire (CHQ). Clin Exp Rheumatol. 2001;19:S25-8.

7. Brasil TB, Ferriani VP, Machado CS. Inquérito sobre a qualidade de vida relacionada à saúde em crianças e adolescentes portadores de artrites idiopáticas juvenis. J Pediatr (Rio J). 2003;79:63-8.

8. Wake M, Hesketh K, Cameron F. The Child Health Questionnaire in children with diabetes: cross-sectional survey or parent and adolescent-reported functional health status. Diabet Med. 2000;17:700-7

9. McCullough N, Parkes J. Use of the Child Health Questionnaire in children with cerebral palsy: a systematic review and evaluation of the psychometric properties. J Pediatr Psychol. 2008;33:80-90

10. Koscik RL, Douglas JA, Zaremba K, Rock MJ, Splaingard ML, Laxova A, et al. Quality of life of children with cystic fibrosis. J Pediatr. 2005;S64-S68.

11. Klatchoian DA, Len CA, Terreri MT, Silva M, Itamoto C, Ciconelli RM, et al. Quality of life of children and adolescents from São Paulo: reliability and validity of the Brazilian version of the Pediatric Quality of Life InventoryTM version 4.0 Generic Core Scales. J Pediatr (Rio J). $2008 ; 84: 308-15$.

12. Patrick DL, Deyo RA. Generic and disease-specific measures in assessing health status and quality of life. Med Care. 1989;27: S217-32.

13. Tucker LB. Whose life is it anyway? Understanding qualiy of life in children with rheumatic diseases. J Rheumatol. 2000;27:8-11.

14. Varni JW, Limbers CA, Burwinkle TM. Impaired health-related quality of life in children and adolescents with chronic condition: a comparative analysis of 10 disease clusters and 33 disease categories/severities utilizing the Peds QLTM 4.0 Generic Core Scale. Health and Quality of Life Outcomes. 2007;5:43.

15. Faleiros FT, Machado NC. Assessment of health-related quality of life in children with functional defecation disorders. J Pediatr (Rio J). 2006;82:421-5.

16. Eiser C, Morse R. Can parents rate their child's health related quality of life? Results of a systematic review. Qual Life Res. 2001; 10:347-57

Correspondence:

Márcia Fernanda Carvalho

Rua Severiano da Fonseca, 421

CEP 21931-220 - Rio de Janeiro, RJ - Brazil

Tel.: +55 (21) 2463.2349, (21) 9988.2858

Fax: +55 (21) 2462.0691

E-mail: marciafcarvalho@globo.com 